$\mathrm{Oz}$

Volume 13

Article 10

$1-1-1991$

\title{
A Deciphering of a Wonderful Cipher: Eleven in the architecture of Carlo Scarpa
}

Marco Frascari

Follow this and additional works at: https://newprairiepress.org/oz

\section{(c) (1) $9 \odot$}

This work is licensed under a Creative Commons Attribution-Noncommercial-No Derivative Works 4.0 License.

\section{Recommended Citation}

Frascari, Marco (1991) "A Deciphering of a Wonderful Cipher: Eleven in the architecture of Carlo Scarpa," Oz: Vol. 13. https://doi.org/10.4148/2378-5853.1222

This Article is brought to you for free and open access by New Prairie Press. It has been accepted for inclusion in Oz by an authorized administrator of New Prairie Press. For more information, please contact cads@k-state.edu. 
A Deciphering of a Wonderful Cipher:

Eleven in the architecture of Carlo Scarpa

Marco Frascari

The Beginning Trace:

I am a 13. Anton Francesco Doni was an 18, Antonio Abbondi, called the Scarpagnino, was a 14, called the $11 .^{1}$

\section{Second Trace:}

Weak thinking is a procedure which is neither aggressive nor domineering. Grounded in a convalescent ontology, weak thinking is rather gentle and tangential (Vattimo 1984, 1988, 1990). This is a convincing practice for centering admiration father than developing precise scientific eccentricity. Weak thinking is a militant but discreet philosophy which has recently been translated into the real $m$ of architecture on the pages of some Italian architectural magazines, Casabella, Lotus and the reborn Ottagono (De Sola Morales 1989, Gregotti 1989, Vattimo 1988). Weak thinking, a process of discreet thinking, will lead us to a future of wonderfully discreet architecture.

\section{Third Trace:}

The discrete constructions of Carlo Scarpa are wonderful pieces of discreet architecture. Discretion is a synthetic activity of the intellect. Proceeding from the knowlegde of what architecture is, discretion sets out the means by which the works of wonderful architecture are realized. The excercise of discretion is thus a synthetic activity reversing the Cartesian analytical procedure of $a b$ straction. Discreet architecture is a union of theory and practice, a construction of the discrete parts resulting from the application of imagination to the reality of 36 the art of building.

\section{Fourth Trace:}

In proposing a search for an architecture which produces thauma - vulgarly called wonder-my aim is to suggest an approach to the study of the theories of architecture from a humanistic and playful point if view. Paraphrasing a well known passage in Aristotle's Poetics $(9,2)$ it is possible to say that architectural historians tell us what may have happened while the architects tell us what will come to be. This architectural foreteling is an act of conception, an understanding based on interpretative procedures, a serious play, which analyzes writings, drawings and buildings under the sign of wonder. Wonder stimulates a person to inquiry. It intensifies when the inquiry succeeds and the enigmatic becomes intelligible in a vivid image of conception. In architecture, this topical thinking is a constructive curiosity which observes tectonic events and marvels at them. Architectural theory, then, concerns itself with demonstrative knowledge.

\section{Fifth Trace:}

Numeric essences and semblances are cannonical representations in architecture which allow an assimlation between the art of constructing well and the art of living well. Simulation has its origin in the Greek mimesis, whereas assimilation url stems from the Roman opus. Assimilation has its beginning in the Ars Mamurialis. During the eighth year of the kingdom of Numa Pompilius, a sacred bronze shield fell from the sky. This shield was a presnt from the gods to save the city from a plague. The King told the
Roman people that it was necessary to protect the shield by making 11 other equal to it so whoever tried to steal the sacred object could not distinguish it from the other eleven. A bronze-smith named Mamurius Veturius was the only one to accept the challenge. He made replicas which were so perfect that nobody, not even the king himself, could distinguish the orginal from the assimilated copies. ${ }^{2}$

\section{Half Traces:}

In Architecture, it is true that One and One equal two, but it is also true that $\mathbf{A}$ Pair Of Ones Makes An Eleven.

In current architectural theory and design, numbers are theoretically unbiased mathematical signs. They are instrumental representations, used for graphic and constructive likeness, and as syntactical expressions which determine mathematical associations among the building's parts. They do not carry semantic value in themselves and meaning is achieved only through analogic or symbolic references. A number is meaningles unless it is related to a unit of dimension, in which it becomes a measure or it is related to building elements in which it can represent of Trinities, Tetramorphes or other referential figures.

A semiotic tradition, now alien to us, endowed the use of numbers in architecture with mystical, allegorical, and above all metasphoric significations. The presence of numbers in architectural artifacts not only had an instrumental aspect but also built cosmological resonances. Traces of this tradition are still present in current practice. Many apothegms in the architectural project. One recently revived by formalistic trends is based on the number three: "a perfect facade or building has three parts, a base, a middle and a top." Another apothegm, by Carlo Scarpa whose architecture will play a key role in this discussion of the semiotics of number in architecture, states that "paired columns are better than one." These apothegms are semiotically similar to Pythagorean acusmata, i.e. prescribing statements. These precepts set the interaction between a pragmatic framework and the semantic dimension through a syntactic prescription. In other words, numbers, properly considered, become bearers of meaning in a wonderfully discreet architecture.

As continuous projection of signs, an architectural project is not based an a specific building, but is the result of an uniterrupted act of design based on a continual search for the human measure both in the past and in the future constructed worlds. This continous projection of signs, an act of architectural divination, an infinite semiosis, is realized through the proper use of numbers as a meaningful embodiment of the human measure in the body of the building. Semiosis is the process by which meanings are attached to signs. Symbols, indexes, and icons are a tripartite configuration used to classify signs. ${ }^{3}$ An index is a sign related by contiguity, e.g. smoke is an indexical sign of fire. An icon is a sign 
related by similarity, e.g. a portrait is an iconic sign of the portrayed person. A symbol is a sign related by convention, e.g. a gilded column in the loggia of the Ducal Palace of Venice marks the arch where the Doge used to appear to deliver his speeches to the Venectian people.

The traditional interpretation of numbers distinguishes three currents in the generation of meaning through the use of the numerical lore, viz. the cosmological, the biblical and the magical numbers (Butler 1970: xi). First, the Greek tradition which is based on a geometrical manipulation of numbers, generated a cosmological understanding of the music of the spheres (Butler 1970: 1-21). Second, the tradition of biblical exegesis searched for a harmonic structure of verbal resonances within a paramount text (Butler 1970: 22-30). Third, the tradition of magical sciences, such as Numerology or Nomadia, presented the understanding of numbers as essences of the occult relationships existing between microcosm and macrocosm (Butler 1970: 31-46). These three currents were unified by Renaissance thinkers in a comprehensive view of the reality of things. Numbers became form of forms, exemplary ciphers of all numerable things, both visible and invisible, mortal and immortal, corporeal and ethereal. Numbers evolved as angular angels; they became the messengers of the Semiotica Harmonia generated by the construing and constructing of human, cosmological and theological ends. For instance, Doni (1981: 116) zero as an hermaphrodite figure which, after being coupled with the other nine figures (1 23 456789 ), generated nine decades. The sum of these nine decades is 450 , a perfect number since it is composed of a square, the medium and a hermaphrodite. This perfection could be represented in a city of ten thousand houses, showing the proper proportions. ${ }^{4}$ Architecture was the most powerful manifestation of this tripartite congruity of ends; nevertheless, these traditional interpretations restrict architectural numerology to a very limited understanding of the semiosis of numbers. If they are revived in their his- toric forms, the symbolic nature of the number signs dominates the indexical and iconic dimensions, the real tectonic extent and presence of numbers, forcing them to be minor presences in the process of signification.

To enlarge and enrich the semiosis of numbers in architectural design, it is necessary to understand their tectonic dependency. Numbers are one of the most important tools used by architects, builders, and inhabitants during the daily construction and construing of architectural artifacts. Reusing the above mentioned semiotic triadic model of index, icon, and symbol, three types of signification can be recognized in the usage of numbers and numerals in architecture. The signification is indexical when the number of building elements help to set a relationship between the denotation and connotation in any architectural space, i.e. paired columns become spatial hinges indicating entry on a facade, or are used as a structural markers for generating a direction in a room. A signification is iconic when the numerals of a body of construction represent the numbers associated with the human body. This process uses corporeal tropes as key images for figuring out the chiastic nature of architecture. Just as we think architecture with our bodies, we think our bodies through architecture. The rhetoric of this latter sentence displays a monstrous and curios chiasm, a hiatus, i.e. a mutual ascription of ciphers and figures between the human snd architectural bodies. This bodily hiatus has been evident in the realm of the constructed world since builders used both their own bodies and the bodies of their sacrificial victims for inscribing their constructions with inferential meanings. The representation of architecture in bodies and of bodies in architecture began when the organization of built bodies was approached through a poetic of the labyrinthine quality of the numerals of the human body. This tradition suggested canons for the determination of measures and proportions and for the imagery to be used during the design and construction of buildings.
Leone Battista Alberti, in his treatise, indicates that to achieve congruency or harmony in any architectural project it is necessary to deal with three active factors: numbering (numeratio), dimensioning (finitio), locating (collocatio). Numeratio is the proper selection of a process of numbering to use in building. Alberti indicates that a good number is forty, because "a patient recovers at the end of forty days." In this case as in many other numerical selections, the exegesis of Alberti's text reveals the anthropomorphic origin of numbers. Rene Thom (1974:77) points out, "number as sign grows out of living things." This is a discreet chiasm between the parts of the body which are counted and the parts of the body which are named. It is a rhetorical procedure which uses body parts as tectonic locatives (Ifrah 1987:"11-21). The signification is symbolic when the number of the tectonic elements is conventionally related to other cultural usage of the number. Twelve columns might crudely symbolize the twelve months, the twelve zodiac signs, or the twelve apostles.

In tectonics, numbers must be considered identical with things (Nicholas of Dusa 1989:75), since they are both space and time bound. In this sense this new semiosis in architecture is very close to the Pythagorean figuring out of numbers (Brukert 1962:31) or to Wittgenstein's explanation of the common language manipulation of digits. The resulting architecture is then a "theoretical" discipline based on auctoritas or the authority of the architect's understanding of numbers. Auctoritas is achieved by the implementation of numerical demonstrations in construction. The theory of architecture is established through demonstrations, and Scarpa's authoritative use of eleven is such a demonstration. In a discussion of the use of eleven in architectural semiosis, as I already mentioned, Scarpa's opus is fundamental.

Eleven is both an intriguing numeral and a charming number which demonstrates the semiotic nature of human constructions. In China eleven is the number of the Tao, but it is not taken in the quantitative sense of ten plus one; it signifies the unity of the decade in its wholeness (Franz, 1974:65 \& 147). Eleven appears as a factor, and a multiple, though not by itself, in the Imperial system of measuring: $5^{1 / 2}$ yards are one road, pole or perch, 4 perches make 22 yards which are a chain, 220 yards a furlong, and 1750 [11x160] yards makes a mile (Wells, 1986:82). Eleven is the fifth number in the Lucas sequence: 1347111829 ...(Wells,1986:83). In architecture, the use of eleven is very spare, but its peculiar nature allows a deep analysis of the use of numberical analogies. The use of eleven is a departure from tradition, but it is also the keeping of a tradition. In one lecture, Scarpa pointed out that in his designs, he used numeric manipulation based on the digit and numeral eleven.

I need a certain kind of light and I worked everything on a grid of 5.5 centimeters. This motif seems nothing special,but it is actually rich in expressive scope and movement.. I measured everythiing with the number 11 and 5.5 Since everything was based on multiplication, everything fits and the measurement turns out right. Someone will object that the measurement turns out right. Someone will object that the measurement will end up right even on a grid of 1 centimeter - but it's not true because 50 multiplied by 2 is 100 , while 55 by 2 is 110, and if you add another 55 it makes 165, not 150, and if you double that you get 220 and then 330,440 . In this way you can divide up the parts and you'll never have 150 but 154.

(Scarpa 1986)

The understanding of the peculiarity of the usage of eleven in Scarpa's architecture must begin with consideration of two Byzantine occurences. On one hand, there is the bizarre fact that a total of eleven letters composes the name and the family name of the Venetian architect, C1a2r31405 S6c7a8r9p10a11. On the other hand, in the Italian tradition of construction, the thickness of a standard 
hollow tile partition wall is approximatly $11 \mathrm{~cm}$, although the nominal dimension is $10 \mathrm{~cm}(9 \mathrm{~cm}$ of the tile and $1 / 2 \mathrm{~cm}$ of plaster on both sides ) because in the reality of construction, tiles are never assembled following a perfect plum-line and the reoccurring mistake is corrected in the thickness of the plaster, thus bringing the total width of the partition wall closer to the real dimension of $11 \mathrm{~cm}$.

A stroll in Venice is probably the best way to understand the presence of number in architecture. Walking from the church of San Barnaba-where a magnificent Corinthian order is celebrated by the interlocking of three rows of columns on the corners of beautifully proportioned NeoPalladian facade, ${ }^{5}$ to the church of the Angelo Raffaele, a magnificent baroque elevation with rigorous numerical expressions set on the mystical numbers of a Byzantine plan-there is a small campo, a spot, where it is possible to see how a significant metamorphosis of the constructed environment took place. This campiello, a clearing in the forest of dwelling of Venice, is a place which can open our eyes to the opacity of dwelling. In this privileged locus, light and dark meet in the shades and shadows of edifices to generate an interpretation of the human expression of reality in the facts of construction. This is one of those places where the poetic dimension of dwelling can auspiciously be measured, an opus of architecture where a new semiosis of numbers can be assimilated.

The direct path between San Barnaba and San Angelo Ranffaele leads down Calle Lunga San Barnaba, which, as the name states, is on of the longest Calli in Venice. Just before we reach the beautiful, monumental apses of the church of the Angelo Raffaele, a small bridge ends the Calle by bringing us into a little campo, a campiello. The urbanity of the campiello is controlled spatially by the small facadee of San Sebastiano. Built circa 1540, it was desighed by Antonio Abbondi, better known under the epithet of Scarpagnio. ${ }^{6}$

The facade is a playful metamorphosis of 38 the traditional front elevation of Venetian churches. It illustrates an interesting attempt to introduce into a church front new building elements which did not belong to traditional ecclesiastic designs. Many of the construction elements used by Scarpagnino were borrowed from the secualur tradition of Venetian palace facades. $^{7}$ One anomalous feature is the presence of paired columns on a single projecting pedestal at the edges of the facade. Paired columns had been used in other Venetian constructions such as San Zaccaria and Palazzo Vendramin-Calergi, but in San Sebastiano the effect seem very eccentric. The upper-story columns are shorter than the one below, and to make the two stories the same height, the upper columns were raised on pedestals. The reason for this peculiarity is that the columns predated the design and were used because they were available. The result is a puzzling and disjointed alignment with the other elements composing the facade.

The entry to the group of buildings composing the monastery of San Sebastiano is located on the south side of the campiello. Laid with a perspectival angle, which recalls that of the Imago Urbis of the Ideal Cities, the facade of the entryway is a thaumaturgic piece of architecture. It is the last "autograph piece" designed by Scarpa. The restoration was completed in 1979, exactly one year after Scarpa's death. This critical piece of design is an orsera (a white Istria stone) base within which is located the portal for the Faculty of Literature and Philosophy of the University of Venice, recently relocated within the monastery complex. This discreet assembly of stone pieces contains in its construction the discrete poetry of the number 11 (eleven).

Scarpa created his poetry by metaphorically using found fragments of the constructed world. His poetry was brought into being by the growth of a tradition within the trade of modernity. The relationship between the part and the whole dominates Scarpa's architecture and many critics have labeled his architecture as fragmentary. However, the result is not a discrete architecture of mere instru-

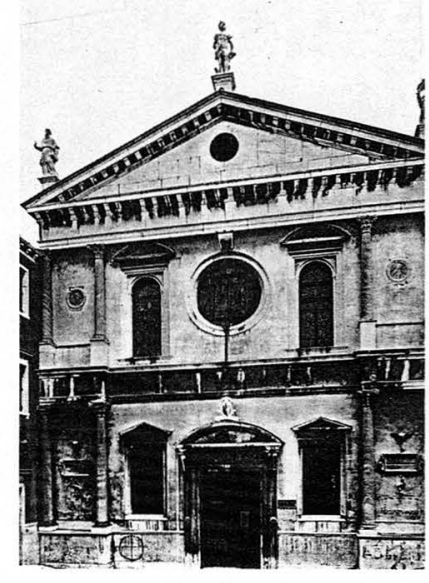

Antonio Abbondi, the Scarpagnino. Facade of San Sebastino, Venice.

Carlo Scarpa. Drawing of rear elevation of the Banca Popolare Drawing of rear elevation of Banca Popolare di Verona

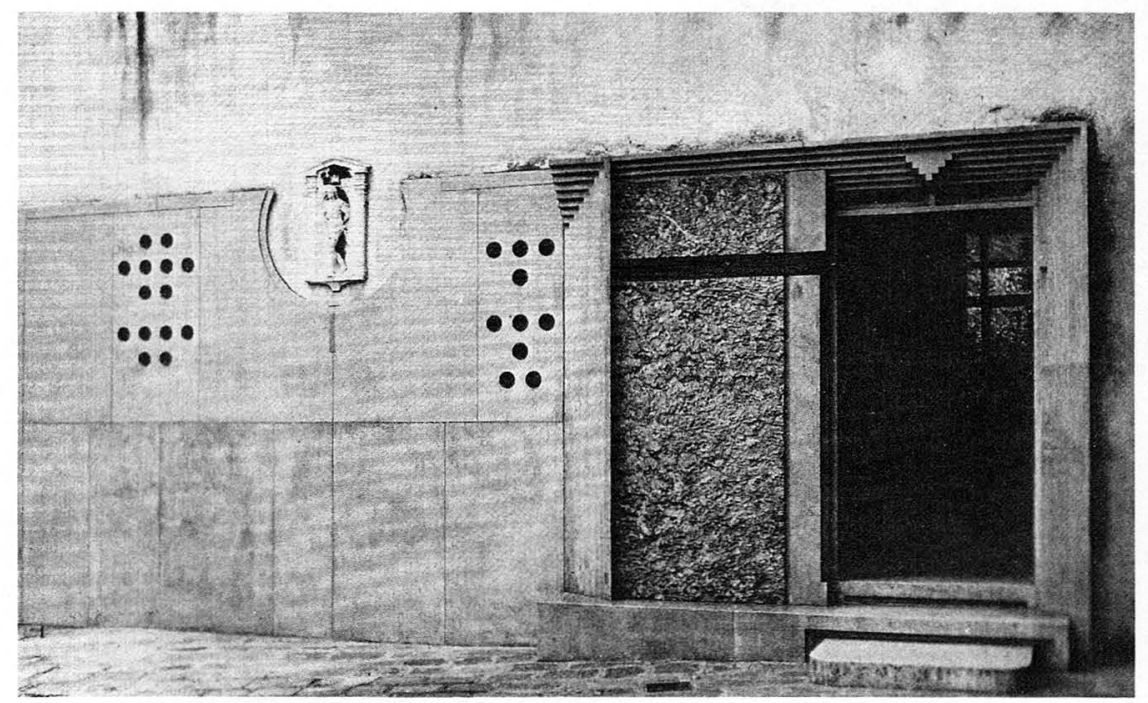

Carlo Scarpa. Facade of the Monastery of San Sebastino, Venice.

mental or symbolic representations; rather, these two kinds of representations are unified in the glorification of the virtual and real joints of a construction. In Scarpa's buildings, the power of a tectonic imagination is the core of the architectural metier, Although interested in the architecture of Aalto, Le Corbusier, Wright, Wagner, Loos, and Hoffmann, Scarpa was above all interested in the stones of Venice. Scarpa's architecture is regional: the architectural traditions of Venice are the hidden representations. Every Scarpa building contains invisible parts of Venice. Scarpa did not design within an historical eclectic dimension. His designs were based on a continuous trade with history producing new building elements to be assimilated in the architecture of Venice. The facades of Scarpa and Scarpagnino are stones of Venice which speak of architecture as embodied knowledge. They demonstrate that architecture is a traditional knowledge which allows translation of ideas from one field to another, and as a way of letting thoughts hanging around. Resting against the old facade of the Monastery of San Sebastiano, Scarpa's stone base enters a productive dialogue with the facade of the Scarpagnino. Thesis and counter-thesis are deveolped, and the argument is resolved in the joint between the two facades, where the lowest of the binary columns set by Scarpagnino engages the base designed by Scarpa. The two windows on 


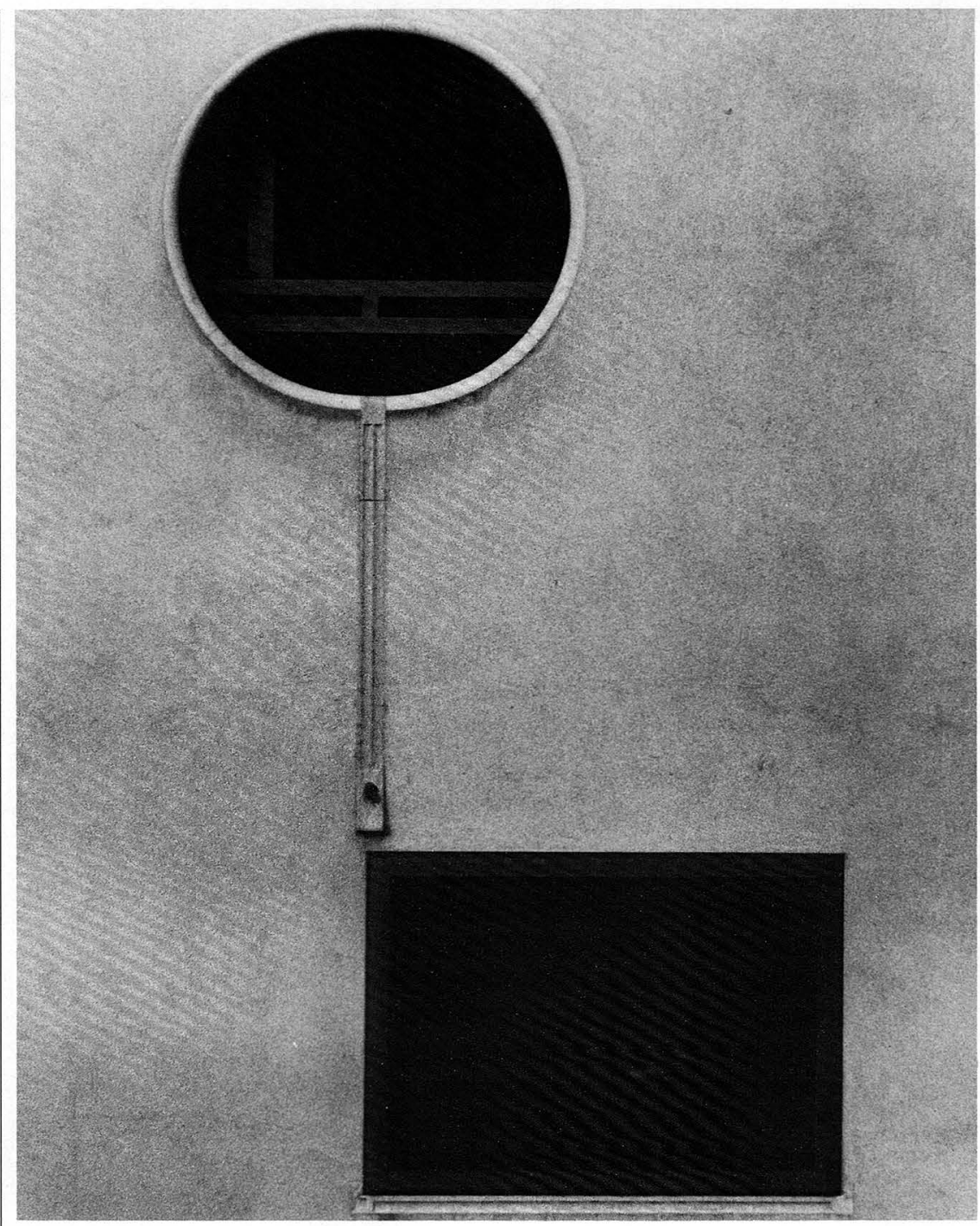

Carlo Scarpa. Round window in the front facade of Banca di Verona.

the ground floor of the monastery have been closed by the slabs of orsera raised by Scarpa against the base of the facade. The memory of these window openings is marked by the original stone lintels showing above the stone base. In Scarpa's design, the windows were replaced by round ventilation holes. Ten round holes replace the window near the door, and sixteen the other. The graphic arrangement of these holes recalls the ancient Greek notational figure for odd numbers, but they are slightly different. What seem to us triangular-odd-numbers are instead square-even-numbers: the triangular composition of the orifices generates an even sum in every opening but one, which of course is the exception that confirms the rule. This
Scarpa's architecture is a discreet and playful project which relates to the traces of tradition. In this specific case, the tradition is the Venetian constructive ability to reconciliate discrete building elements of disparate origin without becoming eclectic. The San Sebastiano project was begun by Scarpagnino when he harmonized pilfered columns with his design of the facade and carried on by Scarpa's attuning numbers and numerals of the ventilation openings, a tradition which finds its most beautiful expression in the small passage connecting the church on the island of San Michele, designed by Mauro Codussi, a 12, with the later addition of the Emiliana chapel.

In his design of the entry facade, Scarpa is also introducing new elements resulting from the transmutation of fertile motifs. Here, the transmuted motif is a zigguratmolding which becomes the solution for any problem of detailing the entry door. This motif has been used by Scarpa on several other occasions, in cast concrete form for a cemetery in a countryside, in red marble for a bank in a dense urban environment, and now in orsera for the entry to an institution of higher learning, in a quiet recess of a historical city. In the latter specific use of the fertile motif, the iconic and indexical signs reveal that architecture is a corporeal project, not a typological composition. The corporeal image imposed on the artifacts by the means of numbers is a significant mask. This image becomes clear in the detail of the step leading to the door, a stone tongue gently protruding from the facade. The module used in the ziggurat is 5.5 centimeters.

Number, in fact, is composed out of itself, since every number is a composite of an even and an odd number. Thus number is composed out of number. Ifyou said the number three is composed of three units, you would be speaking the way someone claims that walls and roof make a bouse when they still exist separately. For if the walls and the roof are separate, no house is composed from them (Nicholas of Cusa 1989:72).

Eleven as a powerful invention of inspired technology finds its best expression in another ecclesiastic building built a few years before $S$. Sebastiano. 8 This is the church of Santa Maria dei Miracoli, designed by Pietro Lombardo. This church has 11 bays in the main body, and its nave is divided by a change of level marked by 11 steps. Outside, on the upper story of the facade, two oculi mark the round-top dozen of the ventilation holes used in the

pediment. The perimeter of these two round openings is decorated by 11 patens of precious marble, a decoration born from the Venetian tradition of slicing pilfered marble columns. Under these two windows there is a vertical dark mark caused by rain deposits. This weathermark become a beauty-mark in Scarpa's solution for the round windows in the Banca Popolare in Verona. In the plaster under the round opening Scarpa has inserted a vertical molding 5.5 centimeters wide. The dark rain mark is controlled by a pair of vertical filetti composing the molding. An ugly effect then becomes a discreet decoration born under the sign of wonder.

The greatest architectural wonder is in the use of proportions and again Cusanus's Layman teaches us:

Without number, it is not possible for proportion to exist. Proportion is the realm of forms, for without a proportion suitable and adapted to a form, the form is not able to appear. As I have said, the form of the spoon is not able to remain once the proportion suitable to it is ruined. It would not have a location. Its proportion is like the aptitude of the surface of the mirror for the reflection of an image. Once this fails, the representation ceases to exist. Observe the way in which the infinite unity of an exemplar is able to appear only in a suitable proportion. Number is such a proportion. (Nicholas of Cusa 1989:72-73)

The proportional geometry of the circles of the windows of Verona is extremely peculiar. They are what Scarpa used to call dynamic circles. They are built by using a circle with a radius of five dimensional units intersected with another circle with the same diameter with the distance between the two centers of one unit. The interior half cirlcles are removed and the two remaining half circles are then connected by two segments equal to one unit. The result of this construction is a dynamic circle which, in one 


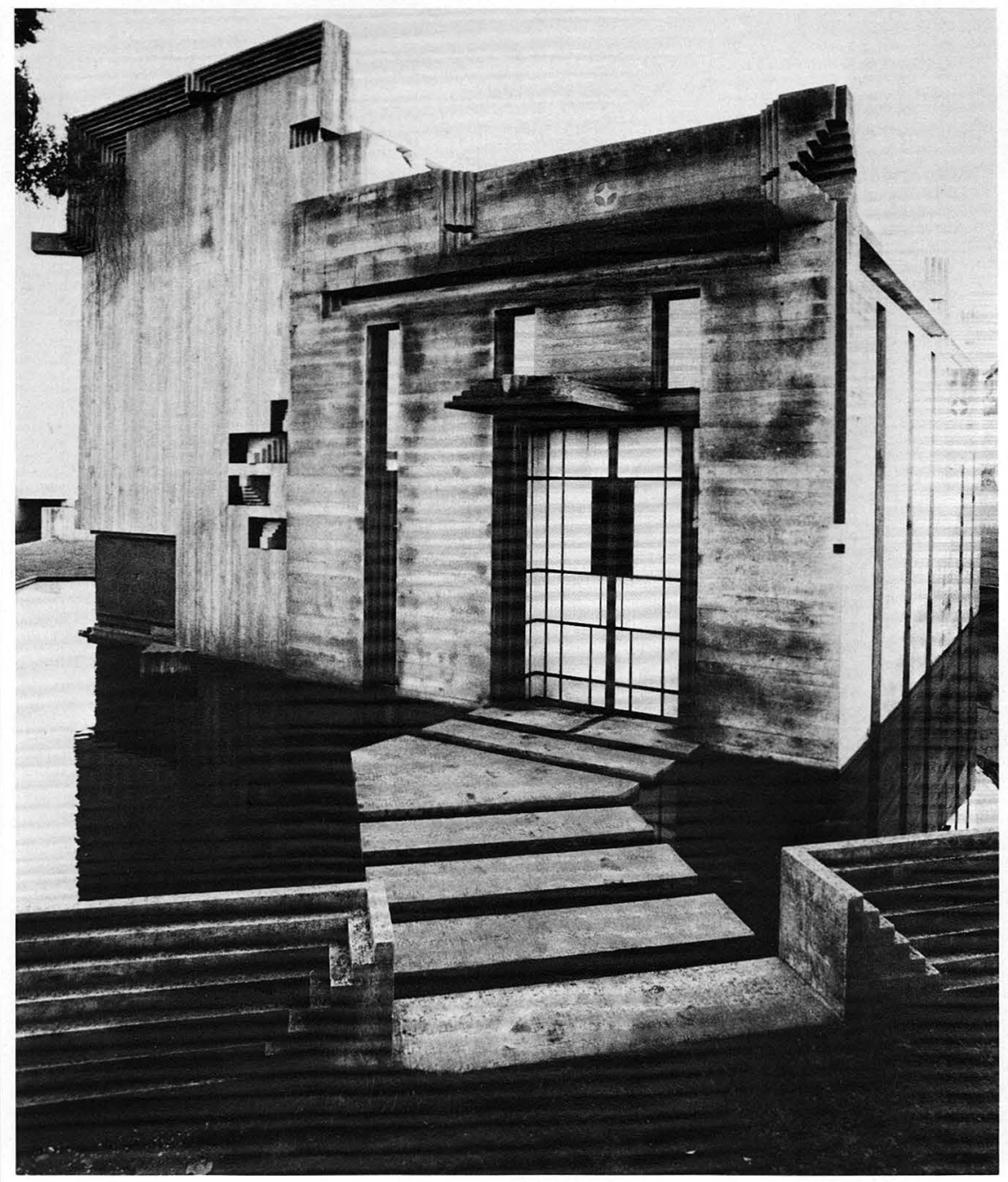

Carlo Scarpa. Elevation of the chapel in the Brion Graveyard, San Vito d'Altivole, Treviso.

direction, has a diameter of eleven units. The dimensional unit used in Verona's windows is the canonical 5.5 centimeters. Scarpa used the same proportional geometry, the molding with the two filetti and the canonical set of endeca-measures in the design of the silver spoon, fork and knife he designed for Cleto Munari on November 6, 1977.

Scarpa's interlocking circles are based on a similar procedure of dynamic and proportional geometry. Two circles are traced and the distance between one exterior arch to the other exterior arch is of eleven units and the centers of the two circles are respectively on the marks of the third and eighth unit. Scarpa, as a good Venetian architect, derived his decorative 40 profiles and figures from the sectioning columns. Scarpa's decorative interlocking circles are thus derived from a metaphorical section of Palladio's refined columns on the front porch of Palazzo Chiericatti in Vicenza, a place where Scarpa, as a child, used to play marbles, as he stated on an interview for Italian television. Scarpa derived his interlocking circles from the section of the two interlocking columns in the colonnade which mark the passage from the line of the front porch to the protruding central part of it.

The most famous instance of these interlocking circles is within the Brion Cemetery, in San Vito d'Altivole. This graveyard is acknowledged by many critics as Scarpa's masterpiece, and the architect himself selected it as his own burial ground. After moving past the natural
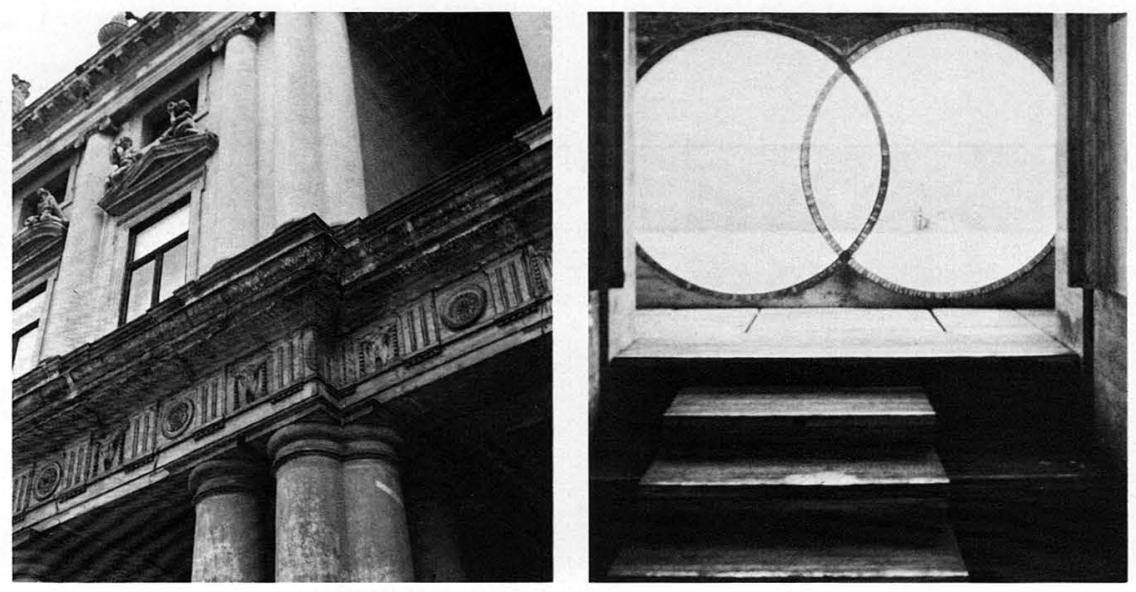

Andrea Palladio. Interlocking columns of Palazzo Chiericatti, Vicenza.

Carlo Sarpa. Interlocking rings at the Brion Graveyard, San Vito d'Altivole, Treviso.

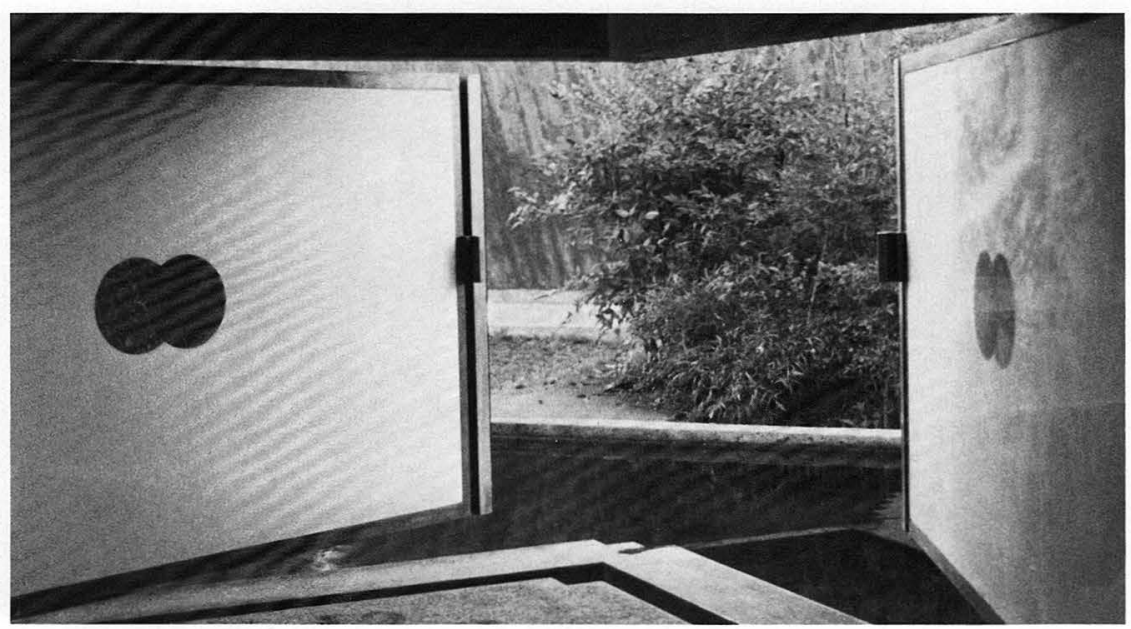

Carlo Scarpa. Interlocking circles in the floor window in chapel at Brion Graveyard.

curtain of weeping willow which masks the entrance of the Brion Mausoleum, the visitor does not face the dim and gloomy interior of a mausoleum, but a short corridor facing a window made with two interlocking rings. Situated in a wall of cast-in-place concrete, this window is framed by two rings made with circularly bent steel I profiles. A decoration of pink and light blue tesseras of Venetian glass mosaic is embedded within the canals of the profile section. One ring is pink and the other is blue. The colors are reversed on the other side of the wall. In these circles, original canonical proportions such as 'root of two,' or the Golden Mean are disregarded; instead, a proportion of duplicity is present a duplicity touched but never fully reached, the duplicity of eleven. Scarpa's funeral was the first to be held in the chapel he designed for the Brions. Scarpa is buried in a piece of ground in a fold of the wall enclosing the Brion graveyard. The grave is ambiguously located between the private and the public sections of the cemetery. A flat lying tombstone designed by his son Tobia marks Scarpa's burial place. The dominant decoration is a grid of small black dots and ziggurat profiles marked on Scarpa's favorite dimension of 5.5 centimeters.

The Greek word sema, which means tomb and grave in one of its many usages, does not merely refer to a place of interment, but implicitly refers to it as marked place, as one where a corpse has been ritually interred. Adolf Loos (1985) clearly indicates that the beginning af ar- 
chitecture is in the mound erected to mark the grave of a peasant in the middle of a wood, not in the over-ornate symbolic palace in the city. The semantic use of numbers has the same ritual beginning, a tectonic presence. Various human activities necessary to the wonder of construction lead to the use of numerals in human activities such as counting, measuring, shaping, forming, estimating, moving, celebrating, calculating, proving, puzzling and so on. A calendar is the result of relating many of those activities to a cosmological changing of seasons. The Roman Calendar was of eleven months. As the Latin origin of the name states, December was the tenth month and January was the eleventh month which marked the ending and the beginning of the year. February did not count; it was a period in between-a period when people suffered of fevers (Februa=Februaris). The first month of the year was March (Sabbaducci 1988:9$12,38-40$ ). January was the month devoted to Janus, the Roman god of beginnings and endings. Embodied by hu- man imagination in powerful architectural elements, Janus is the god of doors, gates, arches, and bridges. He has a pair of faces: one looking toward the future and the other toward the past. Thinking of these peculiar divine qualities of Janus we can trace the tectonic qualities of eleven in the ambiguity between its nature of being a cardinal number between 10 and 12 and its character of being the smallest repunits, a number whose digits are all units. In other words Janus is a perfect mythical representation of the peculiar event that in architecture it is true that Eleven equals One + One. Scarpa secularized this mythical event in the wonderful incidents of his architectural opus, an assimilation of Venetian construction and construing. These secular events are statements of architectural numerology, a discipline of conjectural explanations and divinations which recognizes regional and anthropomorphic tectonics as the footing for the use of numbers in the architectural project, and following Nicholas of Cusa's lead we can assert:

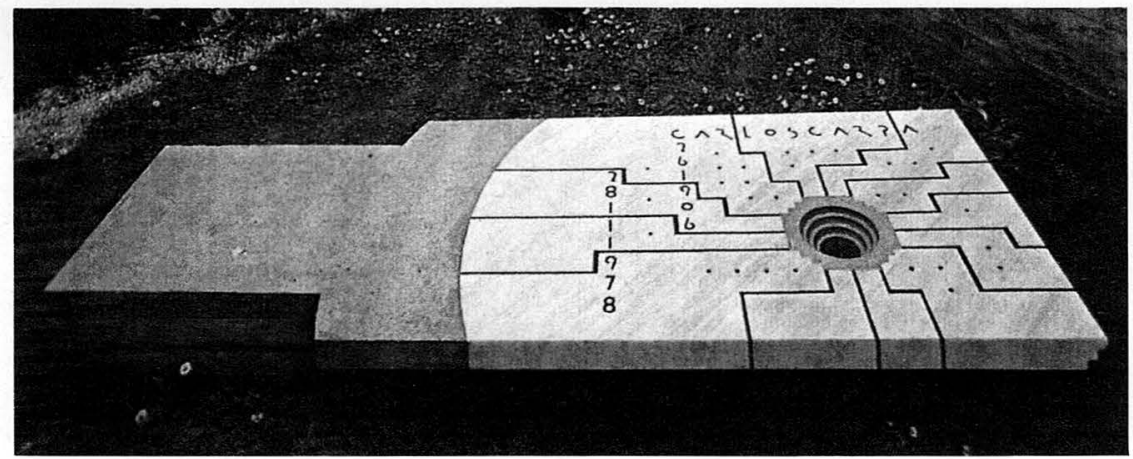

number is the exemplar of our mind's concept.

Without number, the mind cannot do anything.

Neither

Assimilation, conception, discretion, nor measurement would occur if number did not exist. In the absence of number,

things cannot be understood as separate and discrete. Nor without number, is one thing understood

to be substance,

another quality, and so on for the other categories.

Consequently nothing can be understood without numbers, because is the mode of understanding (Nicholas of Cusa 1989:74).

Philadelphia: January 11, 1991.

NOTES

1. This article is dedicated to the memory of Giuseppe Zambonini, a very good friend who was a 17.

2. For a rich discussion of the ars mamuralis and its implications see Perniola (1985;149169).

3. For a discussion of the tripartite structure of index, icon, and symbol see; Eco (1976) and Sebeok (1975).

4. Doni's Numeri is an extrodinary text. The book was dedicated to George Fugger (d. 1560). Through Doni's writings it is possible to set a connection with the leading Renaissance cablists and to the art of memory of Guilio Camillo (Doni, 1981;9-21).

5. This facade was designed by Giuseppe Massari.

6. In Venetian language, scarpagnino is a diminutive form used to indicate a small chisel and scarpa is the form for a normal chisel.

7. For instance, pedimented windows are found only in scuole or palaces. The design attempt by the Scarpagnino is similar to the one developed in the luminous design of the facade of San Michele in Isola designed by Mauro Codussi.

8. Here I am using the locution inspired technology in the sense give to it by L.I.Kahn.

\section{REFERENCES}

Alberti, Leon Battista. Ten Books on Architecture, tr. J. Leoni 1726, Tiranti, 1955.

Brukert, Walter. Lore and Science in Ancient Pythagoreanism, Harvard University Press, Carbridge, 1972. 1962.

Buter, Christopher. Number Symbolism, New York, 1970

De Sola Morales, Ignasi. "Weak Architecture," Ottagono, 92.

Doni, Anton Francesco. I Numeri, A. Del Fante ed Rome, Bulzoni, 1981.

Eco, Umberto. A Theory of Semiotics, Bloomington: Indiana University. Press, 1976.

Franz, Marie-Luise von. Number and Time, Evanston, 1974.

Freidberg, Richard. An Adventurer's Guide to Number
Theory MoGrow-Hill, New York, 1968.

Gregotti, Vittorio. "The Weakness of Criticism," Casabella 562,1990, pp.2-3 \& 63.

Ifrah, Georges. From One to Zero: a Universal History of Numbers, Harmondsworth, 1987.

Le Corbusier (P. Jeanaret). Modulor 1 \& 2, London $1954-58$.

Loos, Adolf. "Architecture," 1910, The Architecture of Adolf Loos, 1985, Precision Press, London.

Menninger, Karl. Number Words and Number Symbols, MIT Cambridge, 1958, 1969.

Nicholas of Cusa. The Layman on Widsom and the Mind, Dovehouse, Ottawa 1989.

Ransdall, Joseph. "On Pierce's Conception of the Iconic Sign," Iconicity, Tübingen, StauffenbingVerlag 1986, pp.51-74.

Sabbaducci, Dario. La Religione di Roma Antica, dal calendario festivo all'ordine cosmico, Il Saggiatore, Milan 1988.

Scarpa, Carlo. "Madrid Lecture," Carlo Scarpa, The Complete Works, eds. F. Dal Co \& G. Mazzariol, New York, Rizzoli, 1986

Sebeok, Thomas, A "Six Species of Signs," Semiotica 13, 1975, pp. 233-260.
Thom Rene, Modeles Mathematiques de la Morphogenese, Paris, UGE, 1974.

Vattimo, Gianni, "Ornament/Monument," The End of Modernity, The John Hopkins University Press, Baltimore 1988, pp. 80-89.

Vattimo, Gianni. "Dialectics, Difference and Weak Thought," Graduate Faculty Philosophy Joumal Vo 10, n.1 1984, pp. 151-165.

Vattimo, Gianni. "The End of Modernity. The End of the Project," Journal of Philosophy and the Visual Arts, 1990, pp. 74-77.

Vitruvius, [Marcus Pollio], On Architecture, tr. \& ed. F. Granger, 2 vols., London, 1931.

Wells, David, The Penguin Dictionary of Curious and Interesting Numbers, Harmondsworth, 1986. Wittgenstein, Ludwig, Philosophical Investigation Blackwell 1953.

Wittgenstein, Ludwig, Wittgenstein's Lectures on the Foundation of Mathematics, 1939, Harvestener Press. Wittkower, Rudolf, Architectural Principles in the Age of Humanism rev ed London, 1962.

Wright, Crispin, Wittgenstein on the Foundation of Mathematics, Harvard University Press, 1980. 